\title{
GMR
}

\section{A clinical study of bone mesenchymal stem cells for the treatment of hepatic fibrosis induced by hepatolenticular degeneration}

\author{
D. Zhang \\ Henan Provincial People’s Hospital, Zhengzhou, Henan Province, China \\ Corresponding author: D. Zhang \\ E-mail: tengjunfang@tom.com
}

Genet. Mol. Res. 16 (1): gmr16019352

Received September 21, 2016

Accepted September 21, 2016

Published March 15, 2017

DOI http://dx.doi.org/10.4238/gmr16019352

Copyright (C) 2017 The Authors. This is an open-access article distributed under the terms of the Creative Commons Attribution ShareAlike (CC BY-SA) 4.0 License.

\begin{abstract}
The efficacy of bone marrow mesenchymal stem cell (BMSC) on liver fibrosis in animal has been proven, but a few studies have been made in human body and few such researches in China. This study was designed to investigate the effect of BMSC treatment on hepatic fibrosis induced by hepatolenticular degeneration and the influence on serological indicators. Sixty patients with liver fibrosis induced by hepatolenticular degeneration were randomly divided into two groups, a penicillamine group and a BMSCs plus penicillamine group, with 30 patients in each. The therapeutic effects on hepatic fibrosis, liver function, and serological indicators were recorded before and after the treatment, and the data were compared. After treatment, serum levels of HA, PCIII, LN, CIV, TIMP-1, and MMP-1 were reduced in both groups $(\mathrm{P}<0.05)$. However, cytokine levels in the BMSCs plus penicillamine group were significantly lower than those in the penicillamine group $(\mathrm{P}<0.05)$. Combination therapy with BMSCs and penicillamine had a significant positive effect on liver fibrosis induced by hepatolenticular degeneration.
\end{abstract}

Key words: Hepatolenticular degeneration; Hepatic fibrosis; BMSCs; Serological indicator; Penicillamine

Genetics and Molecular Research 16 (1): gmr16019352 


\section{INTRODUCTION}

Hepatolenticular degeneration (HLD), also known as Wilson disease (WD), is an autosomal recessive disorder of copper metabolism and is one of the few treatable neural hereditary diseases (Dusek et al., 2015). An abnormal deposition of copper in tissues such as the liver and brain causes tissue and organ damage, and the most common clinical symptoms are cirrhosis and brain injury (Mak and Lam, 2008; Burkhead et al., 2011). Copper has a varying deposition rate, location, and degree and causes a range of complex clinical symptoms. However, all patients display some degree of chronic hepatic lesion because paraeccrisis dysfunction of the biliary passage causes long and slow sedimentation of free copper in liver tissue. Furthermore, liver fibrosis is the main pathological change seen in almost all HLD patients. HLD is a common monogenetic hereditary disorder, and according to a foreign epidemiological investigation, its incidence is one third of ten thousand people, morbidity is 15-25 in a hundred thousand, and it is heterozygous in one in one hundred people (Schilsky, 2009; Corte et al., 2013). At present, there are no domestic disease epidemiology survey data. However, some domestic scholars have statistically analyzed data from nerve hereditary disease specialist outpatients between 1982 and 1991, and the results show that HLD accounted for $10.14 \%$ of patients, making it the second most common single gene genetic disorder in China (Cao et al., 2007).

Cirrhosis is not only the primary pathological change seen in patients with HLD, but also one of the main causes of death. It is therefore of clinical importance to put emphasis on cirrhosis, especially on the early stage of hepatic fibrosis. Hepatic fibrosis is a wound healing process comprising reversible extracellular matrix (ECM) deposition following chronic injury to the liver (Khan et al., 2008). Chronic liver injury, as well as inflammation caused by various factors, can lead to fibrous tissue hyperplasia and deposition, and ultimately hepatic fibrosis. Previous research on hepatic fibrosis concentrated mainly on the synthesis of ECM components, such as hyaluronic acid (HA), laminin (LN), collagen, and fibronectin (Kershenobich Stalnikowitz and Weissbrod, 2003), while more recent studies have focused more on ECM degradation (Gao and Duan, 2002). Matrix metalloproteinases (MMPs) and tissue inhibitors of metalloproteinases (TIMPs) are the major enzymes involved in ECM degradation. Studies have shown that MMP-1 (also known as interstitial collagenase), a basic type of MMP, plays a primary role in ECM degradation. While TIMPs, through inhibition of MMP-1 activity, stop the degradation of ECM in the liver, which causes ECM deposition, leading to hepatic fibrosis, and eventually to cirrhosis.

At present, there is no domestic or foreign literature on treating hepatic fibrosis in HLD patients, and no drugs have been officially approved for clinical anti-hepatic fibrosis treatment. Some drugs do have preventive effects at the early stages, or for a short-term, but treatment is less effective for later-stage cirrhosis, and the drugs have considerable side effects after long-term use. Therefore, it remains an immediate and important task to search for effective treatments of HLD-associated hepatic fibrosis.

With the development and application of basic medicine such as cytology and molecular biology stem cell research has made significant progress. Bone marrow mesenchymal stem cells (BMSCs) that have been differentiated into hepatic cells under the microclimate of the liver have been shown to repair hepatocyte damage, reverse fibrosis, and recover liver function in mice and rats (Abdel Aziz et al., 2007). Clinical studies using autologous bone marrow stem cell transplantation to treat cirrhosis in humans, both in this country and abroad, have

Genetics and Molecular Research 16 (1): gmr16019352 
achieved some success, and have been shown to improve liver function to some extent (Russo et al., 2006). In recent years, we have used BMSCs for the clinical treatment of HLD and have observed their effect on liver function and serum markers of liver fibrosis. This has allowed the effects of BMSCs on hepatic fibrosis in HLD and possible underlying mechanisms to be determined.

\section{MATERIAL AND METHODS}

\section{Materials}

Sixty patients with HLD who were hospitalized in the Department of Neurology at Henan Provincial People's Hospital from January 2012 to January 2015 were selected as subjects in this study. These patients were either newly diagnosed, without any decopper treatment, or subsequent visit patients with no decopper treatment for 6 months to 1 year. All subjects met the diagnostic criteria of HLD, and patients with hepatic diseases caused by other factors, such as hepatic encephalopathy, hepatorenal syndrome, primary liver cancer, severe systemic diseases involving cardiovascular, pulmonary, renal, endocrine, and hematopoietic system and mental disease, were excluded from the study. Using a randomized digital table and randomized remainder number methods, the patients were divided into two groups, penicillamine only and BMSCs plus penicillamine, with 30 patients each group. A normal control group (17 males and 13 females) consisted of healthy subjects with an average age of $27.65 \pm 7.62$ years old, and all underwent examination for liver function, hepatitis A antibody, hepatitis B, hepatitis C, hepatitis D, hepatitis E, and type-B ultrasonic checks for liver, spleen, and kidney. All of their test results were normal. All subjects included in the study provided informed consent.

Consent of Patients and Ethical Committee: The Ethical Committee and all patients agree to the experiments as they are patients at the Henan Provincial People's Hospital. All experimental processes are within the standards of the ethical committee.

\section{Methods}

\section{Therapeutic methods}

1) Penicillamine group: penicillamine (Shanghai Xinyi Pharmaceutical Company) was taken daily at a dose of $40 \mathrm{mg} / \mathrm{kg}$ for 8-16 weeks. 2) Intervention of BMSCs transplantation: 2 $\mathrm{mL} \mathrm{BMSCs} \mathrm{(cell} \mathrm{density} \mathrm{of} 3 \times 10^{6}$ cells $/ \mathrm{mL}$ ) and $100 \mathrm{~mL}$ saline were transplanted into the body through a vein every 10 days. One course of treatment consisted of three injections. In addition, a dose of $40 \mathrm{mg} / \mathrm{kg}$ penicillamine was taken orally three times a day for 12 successive weeks.

\section{BMSC collection, isolation, and transplantation}

All of these procedures were performed under sterile conditions. After local anesthesia, a No. 18 bone marrow puncture needle was used to perform a puncture at the ambilateral posterior superior iliac spine and extract about $50-80 \mathrm{~mL}$ bone marrow. The extracted bone marrow was mixed with heparin for anticoagulation, and samples were centrifuged to isolate the fat layer, which was prepared into a cell suspension by dilution with an equal amount

Genetics and Molecular Research 16 (1): gmr16019352 
of DMEM culture media. The bone marrow was added to percoll separating medium and centrifuged at $1200 \mathrm{rpm}$ at room temperature for $25 \mathrm{~min}$. The cell interface layer was carefully removed and eluted 3 times with saline, then centrifuged at $1500 \mathrm{rpm}$ for $5 \mathrm{~min}$. Cells were resuspended in saline then counted and adjusted to $1 \times 10^{8}$ to $10 \times 10^{8} / \mathrm{L}$. Remaining cells were stored at $4^{\circ} \mathrm{C}$ for backup. BMSCs $\left(2 \mathrm{~mL}\right.$, at a density of $3 \times 10^{6}$ cells $\left./ \mathrm{mL}\right)$ and $100 \mathrm{~mL}$ saline were transplanted into the body through a vein every 10 days. Three injections were a treatment course.

\section{Laboratory examination}

Peripheral blood $(5 \mathrm{~mL})$ was drawn from all patients before treatment and 12 weeks after treatment. Serum was isolated by centrifugation, and was stored at $-20^{\circ} \mathrm{C}$. A radioimmunoassay kit (Shanghai Haiyan Medical Biological Technology Co., Ltd.) was used to detect changes in HA, precollagen III (PCIII), LN, collagen (CIV) in the serum. The determination principle is a competitive radioimmunoassay, and the specific operation steps are in line with the manufacturer's specifications. Normal values for HA, PCIII, LN, and CIV are 0-100, 0-120, 101.7-135, and 46.5-90.5 ng/mL, respectively. An ELISA kit (R\&D Systems, Minneapolis, MN, USA) was used to determine changes in MMP-1, TIMP-1, transforming growth factor $-\beta 1$ (TGF- $\beta 1)$ and tumor necrosis factor (TNF- $\alpha$ ). Vital signs and incidence of adverse reactions in the patients were observed during treatment.

\section{Statistical methods}

The SPSS 19.0 software was used for statistical analysis. Measurement data are reported as means $\pm \mathrm{SD}$. All statistical analyses were based on normal distribution and homogeneity test of variance. Variances of repeated measurement data were analyzed. P < 0.05 was considered statistically significant.

\section{RESULTS}

\section{Comparison of general data}

Penicillamine group: 17 males and 13 females; average age $32.10 \pm 10.36$ years; course of disease 8 months to 4 years. BMSCs + penicillamine group: 16 males and 14 females; average age $30.98 \pm 11.25$; course of disease 6 months to 4 years. There was no statistical difference in terms of age, gender, and course of disease (Table 1).

\section{Table 1. Comparison of patients' basic data.}

\begin{tabular}{l|c|c|c|c}
\hline Groups & Cases & Gender (male/female, case) & Age (means \pm SD, year) & Course of disease (month) \\
\hline Penicillamine & 30 & $17 / 13$ & $32.10 \pm 10.36$ & $28.1 \pm 12.6$ \\
\hline BMSCs + penicillamine & 30 & $16 / 14$ & $30.98 \pm 11.25$ & $25.5 \pm 13.9$ \\
\hline P & & 0.795 & 0.847 & 0.797 \\
\hline
\end{tabular}

\section{Comparison of serum fibrosis treatment between HLD non-treatment group and normal control group}

Levels of the three serum markers HA, LN and PCIII reflect the composition of liver 
fiber. As shown in Table 2, levels of the 3 markers in the 60 HLD patients without treatment were obviously higher than the control group $(\mathrm{P}<0.01)$. Markers that indicate liver fiber degradation, CIV and TIMP-1, were also increased $(\mathrm{P}<0.01)$; while MMP-1 levels were lower $(\mathrm{P}<0.01)$.

Table 2. Comparison of serum liver fibrosis markers in HLD non-treatment group and normal control group
$($ means $\pm \mathrm{SD})$.
\begin{tabular}{l|c|c|c}
\hline Serum liver fibrosis markers & Normal control group $(\mathrm{N}=20)$ & HLD non-treatment group $(\mathrm{N}=60)$ & $\mathrm{P}$ \\
\hline Hepatic fibrosis composition markers HA $(\mathrm{ng} / \mathrm{mL})$ & $52.49 \pm 11.50$ & $201.66 \pm 14.28$ & $<0.01$ \\
\hline $\mathrm{LN}(\mathrm{ng} / \mathrm{mL})$ & $120.02 \pm 12.52$ & $173.28 \pm 10.77$ & $<0.01$ \\
\hline PCIII $(\mathrm{ng} / \mathrm{mL})$ & $85.45 \pm 14.29$ & $180.60 \pm 14.28$ & $<0.01$ \\
\hline Hepatic fibrosis degradation markers CIV $(\mathrm{ng} / \mathrm{mL})$ & $47.36 \pm 6.89$ & $129.32 \pm 15.09$ & $<0.01$ \\
\hline MMP-1 $(\mathrm{ng} / \mathrm{mL})$ & $152.06 \pm 15.78$ & $120.17 \pm 11.64$ & $<0.01$ \\
\hline TIMP-1 $(\mathrm{ng} / \mathrm{mL})$ & $44.69 \pm 6.85$ & $60.59 \pm 9.48$ & $<0.01$ \\
\hline MMP-1/TIMP-1 $(\mathrm{ng} / \mathrm{mL})$ & $3.62 \pm 0.48$ & $2.01 \pm 0.23$ & $<0.01$ \\
\hline
\end{tabular}

\section{Changes in liver fibrosis markers after treatment}

Tables 3 and 4 show levels of liver fibrosis markers before and after treatment. As shown in Table 3, markers that reflect liver fibrosis, serum HA, LN and PCIII fell after treatment $(\mathrm{P}<0.05)$. Markers that reflect degradation of liver fibrosis, serum CIV, were also reduced. Table 4 shows that levels of MMP-1, a marker of degradation of liver fibrosis, were increased after treatment, whereas levels of TIMP-1, a marker of inhibition of degradation of liver fibrosis, were decreased compared to those before treatment $(\mathrm{P}<0.05)$. Serum levels of MMP-1/TIMP-1 were increased $(\mathrm{P}<0.05)$.

Table 3. Changes of serum fibrosis markers before and after treatment.

\begin{tabular}{l|l|c|c|c|c}
\hline \multicolumn{2}{c|}{ Group } & HA & LN & PCIII & CI-V \\
\hline \multirow{2}{*}{ Penicillamine group } & Before treatment & $199.28 \pm 13.82$ & $174.51 \pm 11.75$ & $179.80 \pm 13.81$ & $128.60 \pm 15.87$ \\
\cline { 2 - 6 } & After treatment & $119.45 \pm 11.05^{*}$ & $127.39 \pm 7.67^{*}$ & $136.87 \pm 12.29^{*}$ & $97.59 \pm 10.04^{*}$ \\
\hline \multirow{2}{*}{ BMSCs plus penicillamine group } & Before treatment & $201.96 \pm 15.85$ & $172.17 \pm 9.89$ & $181.03 \pm 15.44$ & $129.84 \pm 14.36$ \\
\cline { 2 - 6 } & After treatment & $108.69 \pm 10.17^{* \#}$ & $85.00 \pm 6.77^{* \#}$ & $91.24 \pm 7.03^{* \#}$ & $68.14 \pm 5.34^{* *}$ \\
\hline
\end{tabular}

$* \mathrm{P}<0.05$ after the treatment; ${ }^{\mathrm{P}}<0.05$ when compared with penicillamine group.

Table 4. Changes of MMP-1, TIMP-1, and MMP-1/TIMP-1 before and after treatment.

\begin{tabular}{l|l|c|c|c}
\hline \multicolumn{2}{l|}{ Group } & MMP-1 & TIMP-1 & MMP-1/TIMP-1 \\
\hline \multirow{2}{*}{ Penicillamine group } & Before treatment & $120.57 \pm 11.05$ & $60.98 \pm 9.77$ & $2.05 \pm 0.26$ \\
\cline { 2 - 5 } & After treatment & $133.10 \pm 12.85^{*}$ & $48.02 \pm 6.64^{*}$ & $2.44 \pm 0.29^{*}$ \\
\hline \multirow{2}{*}{ BMSCs plus penicillamine group } & Before treatment & $121.16 \pm 12.48$ & $59.24 \pm 8.89$ & $1.98 \pm 0.23$ \\
\cline { 2 - 6 } & After treatment & $148.05 \pm 13.65^{* \#}$ & $33.27 \pm 5.73^{* \#}$ & $2.41 \pm 0.31^{* \#}$ \\
\hline
\end{tabular}

$* \mathrm{P}<0.05$ when compared with indicators before treatment; ${ }^{*} \mathrm{P}<0.05$ when compared with penicillamine group.

\section{Changes in serum TGF- $\beta 1$ and TNF- $\alpha$ in patients from the two groups before and after treatment}

Table 5 shows levels of serum TGF- $\beta 1$ and TNF- $\alpha$ in patients from the two groups before and after treatment. Levels of serum TNF- $\alpha$ and TGF- $\beta 1$ in the penicillamine group and the BMSCs plus penicillamine group were significantly higher than the normal control

Genetics and Molecular Research 16 (1): gmr16019352 
group $(\mathrm{P}<0.05)$. After treatment, levels of serum TNF- $\alpha$ and TGF- $\beta 1$ fell significantly $(\mathrm{P}$ $<0.05)$ in the BMSCs plus penicillamine group, and also decreased in the penicillamine group but with no statistical difference $(\mathrm{P}>0.05)$. Comparison between the two groups after treatment indicates that the BMSCs plus penicillamine group was more effective at reducing serum TNF- $\alpha$ and TGF- $\beta 1$ levels.

Table 5. Changes of serum TGF- $\beta 1$ and TNF- $\alpha$ before and after treatment (means \pm SD).

\begin{tabular}{l|l|cc|}
\hline \multicolumn{2}{l|}{ Group } & TGF- $\beta 1(\mathrm{ng} / \mathrm{mL})$ & TNF- $\alpha(\mathrm{ng} / \mathrm{mL})$ \\
\hline \multirow{2}{*}{ Penicillamine group. } & Before treatment & $36.81 \pm 8.27^{*}$ & $34.57 \pm 5.83^{*}$ \\
\cline { 2 - 4 } & After treatment & $31.12 \pm 7.52$ & $32.05 \pm 5.76$ \\
\hline \multirow{2}{*}{ BMSCs plus penicillamine group } & Before treatment & $37.64 \pm 10.02^{*}$ & $32.47 \pm 6.81^{*}$ \\
\cline { 2 - 4 } & After treatment & $24.84 \pm 7.62^{\# \Delta}$ & $21.23 \pm 5.10^{\# \Delta}$ \\
\hline Normal control group & & $10.58 \pm 1.89$ & $8.83 \pm 1.56$ \\
\hline
\end{tabular}

${ }^{*} \mathrm{P}<0.05$ when compared with normal control group; ${ }^{\mathrm{P}}<0.05$ when compared with indicators before treatment in the same group; ${ }^{\wedge} \mathrm{P}<0.05$ when compared with indicators in control group after treatment.

\section{Changes in liver function in patients from the two groups before and after treatment}

Changes of liver function in patients from the two groups before and after treatment are shown in Table 6. Before treatment, there was no significant difference in TBIL, ALT and AST values between the penicillamine group and the BMSCs plus penicillamine group ( $\mathrm{P}>$ 0.05). However, after treatment, TBIL, ALT, and AST values were reduced in the BMSCs plus penicillamine group $(\mathrm{P}<0.05)$. TBIL, ALT, and AST values in the penicillamine group also decreased but with no statistical significance $(P>0.05)$. In general, changes in TBIL, ALT and AST values between the two groups after treatment were statistically significant $(\mathrm{P}<0.05)$, indicating that the BMSCs plus penicillamine group improved TBIL, ALT and AST values more effectively than the penicillamine group.

Table 6. Changes of liver function before and after treatment.

\begin{tabular}{l|c|c|c|c}
\hline \multirow{2}{*}{ Liver function indicators } & \multicolumn{2}{|c|}{ Penicillamine group } & \multicolumn{2}{c}{ BMSCs plus penicillamine group } \\
\cline { 2 - 5 } & Before treatment & After treatment & Before treatment & After treatment \\
\hline TBIL $(\mu \mathrm{M})$ & $50.26 \pm 22.34$ & $45.11 \pm 23.89$ & $52.40 \pm 20.14$ & $36.67 \pm 21.88^{* \#}$ \\
\hline ALT $(\mathrm{IU} / \mathrm{L})$ & $59.46 \pm 26.20$ & $51.37 \pm 19.88$ & $58.25 \pm 25.69$ & $31.98 \pm 20.10^{* \#}$ \\
\hline AST $(\mathrm{IU} / \mathrm{L})$ & $53.59 \pm 23.12$ & $48.97 \pm 18.98$ & $56.54 \pm 18.73$ & $39.27 \pm 16.72^{* \#}$ \\
\hline
\end{tabular}

$* \mathrm{P}<0.05$ when compared with indicators before treatment; ${ }^{*} \mathrm{P}<0.05$ when compared with indicators in control group after treatment.

\section{Incidence of adverse reactions for patients}

A total of 30 patients received BMSC treatment. After treatment, one patient experienced local pain and three patients had a fever, but all were treated appropriately. There was one case of a reduced white blood cell count, which recovered after granulocyte colonystimulating factor treatment. No other patients had adverse reactions to the treatment and there were no deaths within the 12-week time period, showing a high short-term survival rate. Of the 30 patients that received penicillamine treatment, there were five cases of fever, three cases of rash, seven cases of nausea, and three cases of emesis, all of which were treated appropriately. No deaths occurred within the 12-week period.

Genetics and Molecular Research 16 (1): gmr16019352 


\section{DISCUSSION}

Copper in the serum of patients with HLD integrates with protein deposits in the liver, resulting in hepatic fibrosis, and finally to cirrhosis (Huster and Lutsenko, 2007). Hepatic fibrosis is a wound healing response to various chronic liver injuries and is characterized mainly by abnormal deposition of ECM (Jiang and Zhang, 2000). Studies have shown that hepatic fibrosis, and even early cirrhosis, is reversible (Pol et al., 2004; Wallace et al., 2008). Therefore, an early and accurate diagnosis and assessment of the development of liver fibrosis has fundamental significance for intervention therapy and the prognosis of HLD patients with hepatic fibrosis. At present, serological examinations include mainly HA, PCIII, LN, and CIV, etc. levels (Bolarin and Azinge, 2007; Guo et al., 2009; Qian et al., 2014), which are referred to as "the four indicators of hepatic fibrosis", and have become the most commonly used noninvasive method for detecting hepatic fibrosis. A direct relationship between hepatic fibrosis and these four serological indicators has been proven in many animal experiments and clinical studies. Intensive studies into the mechanism of ECM degradation found that MMPs and TIMPs play an important role in hepatic ECM degradation (Leroy et al., 2004; Jeong et al., 2006; Fontana et al., 2008; Gieling et al., 2008; Kara et al., 2008). It is therefore of great value to study the dynamic process of hepatic fibrosis proliferation and degradation, to determine the degree of hepatic fibrosis and to evaluate the effects of anti-hepatic fibrosis treatments.

Orthotropic liver transplantation is the most effective treatment for advanced liver cirrhosis, but its clinical application is limited (Dutkowski et al., 2015). Since the discovery of bone marrow-derived liver stem cells by Petersen et al. (1999), hepatologists have been exploring ways to use these cells to treat liver disease. Due to the extensive differentiation potential of BMSCs, they have become the most attractive cell source in regeneration medicine and have opened up a new chapter in research into liver injury. In particular, Schwartz et al. (2002) demonstrated that the progenitor cells could differentiate into functional hepatocytelike cells.

In recent years, BMSCs have been used to treat various diseases and have been shown to improve hepatic fibrosis to some extent (Usunier et al., 2014). Studies have shown that six-months after an intravenous injection of cultured BMSCs, patients' liver function indexes, pathological results of hepatic tissue and color Doppler ultrasound were improved, indicating the safety and effectiveness of BMSCs for treating cirrhosis (Mohamadnejad et al., 2007). Several additional reports have shown successful BMSC treatment of patients with hepatic fibrosis (Terai et al., 2006; Kim et al., 2010; Amer et al., 2011; Saito et al., 2011).

BMSCs labeled with green fluorescent protein (EGFP) were used to reconstitute the bone marrow in mice after systemic irradiation, then were injected into $\mathrm{CCL}_{4}$-treated mice to make a cirrhotic mouse model (Higashiyama et al., 2007). This study showed that at the peak of fibrosis formation, large numbers of $\mathrm{EGFP}^{+}$cells colonized the liver, some of which expressed MMP-13 (interstitial collagenase) and MMP-9, which play a role in promoting cordal fiber dissolution and anti-fibrosis. Bone marrow mobilization by G-CSF enabled more BMSCs to colonize the liver and to express more MMP-9, which strengthened the anti-fibrosis effect (fibrosis range shrink). Transplantation of P1 generation BMSCs into rats with early fibrosis effectively promoted liver function recovery and reduced the degree of hepatic fibrosis. Transplantation of BMSCs during the process of $\mathrm{CCL}_{4}$-induced liver injury significantly reduced the degree of fibrosis (Fang et al., 2004). BMSCs mainly function through paracrine signaling via IL-10 and TNF- $\alpha$ (Parekkadan et al., 2007). Results from the present study

Genetics and Molecular Research 16 (1): gmr16019352 
showed that HA, PCIII, LN, and CIV levels in serum were markedly reduced during treatment with BMSCs, indicating that BMSCs can improve hepatic fibrosis.

Transplantation of hepatocyte-like cells, induced in vitro from BMSCs, into mice with acute liver injury resulted in a noticeable reduction in levels of indicator ALT and TBIL after one week, while levels of TP and ALB returned to normal (Yang, 2009). Results in this study show that levels of indicator TBIL, ALT and AST had significant fall after the treatment of BMSCs, which indicates that BMSCs promote the recovery of liver function to varying degrees.

In terms of the degradation mechanism of hepatic fibrosis, improving collagenase activity or reducing inhibitor activity can promote ECM degradation, which is significant for reversing hepatic fibrosis. In the present study, changes in serum indicators after treatment, such as a reduction in TIMP-1, an increase in MMP-1, and a reduction in TIMP-1/MMP-1, reflect a recovery of hepatic fibrosis to some extent.

It has been shown that BMSCs secrete various cytokines and growth factors, such as HGF, ILs, SCF, SDF- $1 \alpha$, TGF- $\beta$, and TNF- $\alpha$ (Oe et al., 2005; Lv and Tan, 2008). HGF not only induces BMSCs to differentiate into hepatic cells but also inhibits the production of TGF- $\beta$ and protects the liver from fibrosis and reduces antiapoptotic activity, and thus improve survival rate. Furthermore, the primary cytokine for activation of stellate cells is TGF- $\beta$, but whether it plays any role in fibrosis and heterocyst reduction by BMSCs requires further research. According to previous studies (Sakaida et al., 2005), the anti-fibrosis effect of BMSCs occurs by inhibiting TGF- $\beta$ secretion to reduce activation of hepatic stellate cells.

Results from the current study show that relatively few patients displayed any allergic reaction, rejection reaction, or other adverse reactions following BMSC treatment, indicating that BMSCs are safe and efficient in treating for hepatic fibrosis induced by hepatolenticular degeneration.

While, the application of BMSCs to treat hepatic fibrosis has achieved promising results, there are still problems. For example, the specific mechanism by which the cells affect hepatic disease is not yet clear. In addition, the long-term treatment efficacy, adverse reactions, the scope of their application and other problems require further investigation. However, the present study clearly demonstrated that the application of BMSCs plus penicillamine provides a new direction for hepatic fibrosis treatment in HLD patients, which is expected to provide a new approach for the treatment of this disease.

\section{ACKNOWLEDGMENTS}

I would like to thank all authors who contributed to this paper in terms of advice and comments. Research supported by "Basic and Frontier Technology Research Planning Project in Henan Province China" - Study on correlation between ATP7B mutation and Hepatolenticular degeneration (Grant: \#22300410259), and "Scientific Problem-Tackling Planning Project in Zhengzhou County Henan Province China" - Clinical study on bone mesenchymal stem cells on treatment of hepatic fibrosis induced by Hepatolenticular degeneration (Grant: \#121PPTGG494-1).

\section{REFERENCES}

Abdel Aziz MT, Atta HM, Mahfouz S, Fouad HH, et al. (2007). Therapeutic potential of bone marrow-derived mesenchymal stem cells on experimental liver fibrosis. Clin. Biochem. 40: 893-899. http://dx.doi.org/10.1016/j.

Genetics and Molecular Research 16 (1): gmr16019352 
clinbiochem.2007.04.017

Amer ME, El-Sayed SZ, El-Kheir WA, Gabr H, et al. (2011). Clinical and laboratory evaluation of patients with end-stage liver cell failure injected with bone marrow-derived hepatocyte-like cells. Eur. J. Gastroenterol. Hepatol. 23: 936941. http://dx.doi.org/10.1097/MEG.0b013e3283488b00

Bolarin DM and Azinge EC (2007). Biochemical markers, extracellular components in liver fibrosis and cirrhosis. Nig. $Q$. J. Hosp. Med. 17: 42-52. http://dx.doi.org/10.4314/nqjhm.v17i1.12541

Burkhead JL, Gray LW and Lutsenko S (2011). Systems biology approach to Wilson's disease. Biometals 24: 455-466. http://dx.doi.org/10.1007/s10534-011-9430-9

Cao BQ, Lin JZ, Zhong YS, Huang SB, et al. (2007). Autologous bone marrow cells transplantation via portal vein for the treatment of cirrhotic patients with hepatic dysfunction. Chin. J. Gen. Surg. 22: 386-389.

Corte CD, Pietrobattista A and Nobili V (2013). Zinc and Treatment of Wilson's disease [M]// Encyclopedia of Metalloproteins. Springer, New York, 2391-2392.

Dusek P, Litwin T and Czlonkowska A (2015). Wilson disease and other neurodegenerations with metal accumulations. Neurol. Clin. 33: 175-204. http://dx.doi.org/10.1016/j.ncl.2014.09.006

Dutkowski P, Linecker M, DeOliveira ML, Müllhaupt B, et al. (2015). Challenges to liver transplantation and strategies to improve outcomes. Gastroenterology 148: 307-323. http://dx.doi.org/10.1053/j.gastro.2014.08.045

Fang B, Shi M, Liao L, Yang S, et al. (2004). Systemic infusion of FLK1(+) mesenchymal stem cells ameliorate carbon tetrachloride-induced liver fibrosis in mice. Transplantation 78: 83-88. http://dx.doi.org/10.1097/01. TP.0000128326.95294.14

Fontana RJ, Goodman ZD, Dienstag JL, Bonkovsky HL, et al.; HALT-C Trial Group (2008). Relationship of serum fibrosis markers with liver fibrosis stage and collagen content in patients with advanced chronic hepatitis C. Hepatology 47: 789-798. http://dx.doi.org/10.1002/hep.22099

Gao TH and Duan FL (2002). TIMPs and hepatic fibrosis. Chin. J. Gastroenterol. Hepatol. 3: 200-202.

Gieling RG, Burt AD and Mann DA (2008). Fibrosis and cirrhosis reversibility - molecular mechanisms. Clin. Liver Dis. 12: 915-937, xi. http://dx.doi.org/10.1016/j.cld.2008.07.001

Guo JX, Ma HB, Li YL, Mao YL, et al. (2009). Evaluation of the ELISA and the enhanced chemiluminescence immunoassay in use to determine the serum markers for liver fibrosis. Chin. J. Exp. Clin. Virol. 23: 71-73.

Higashiyama R, Inagaki Y, Hong YY, Kushida M, et al. (2007). Bone marrow-derived cells express matrix metalloproteinases and contribute to regression of liver fibrosis in mice. Hepatology 45: 213-222. http://dx.doi. org/10.1002/hep. 21477

Huster D and Lutsenko S (2007). Wilson disease: not just a copper disorder. Analysis of a Wilson disease model demonstrates the link between copper and lipid metabolism. Mol. Biosyst. 3: 816-824. http://dx.doi.org/10.1039/ $\underline{\mathrm{b} 711118 \mathrm{p}}$

Jeong WI, Do SH, Jeong DH, Hong IH, et al. (2006). Kinetics of MMP-1 and MMP-3 produced by mast cells and macrophages in liver fibrogenesis of rat. Anticancer Res. 26 (5A): 3517-3526.

Jiang HQ and Zhang XL (2000). The mechanism of hepatic fibrosis. World Chin. J. Digestology 8: 687-689.

Kara E, Coşkun T, Kaya Y, Yumuş O, et al. (2008). Effects of silymarin and pentoxifylline on matrix metalloproteinase-1 and -2 expression and apoptosis in experimental hepatic fibrosis. Curr. Ther. Res. Clin. Exp. 69: 488-502. http:// dx.doi.org/10.1016/j.curtheres.2008.12.003

Kershenobich Stalnikowitz D and Weissbrod AB (2003). Liver fibrosis and inflammation. A review. Ann. Hepatol. 2: $159-163$.

Khan AA, Parveen N, Mahaboob VS, Rajendraprasad A, et al. (2008). Safety and efficacy of autologous bone marrow stem cell transplantation through hepatic artery for the treatment of chronic liver failure: a preliminary study. Transplant. Proc. 40: 1140-1144. http://dx.doi.org/10.1016/j.transproceed.2008.03.111

Kim JK, Park YN, Kim JS, Park MS, et al. (2010). Autologous bone marrow infusion activates the progenitor cell compartment in patients with advanced liver cirrhosis. Cell Transplant. 19: 1237-1246. http://dx.doi. org/10.3727/096368910X506863

Leroy V, Monier F, Bottari S, Trocme C, et al. (2004). Circulating matrix metalloproteinases 1, 2, 9 and their inhibitors TIMP-1 and TIMP-2 as serum markers of liver fibrosis in patients with chronic hepatitis C: comparison with PIIINP and hyaluronic acid. Am. J. Gastroenterol. 99: 271-279. http://dx.doi.org/10.1111/j.1572-0241.2004.04055.x

Lv TM and Tan JM (2008). Relationship between transforming growth factor-beta 1 genotype and chronic renal allograft rejection. J. Clin. Rehabil. Tissue. Eng. Res 12: 7935-7938.

Mak CM and Lam CW (2008). Diagnosis of Wilson's disease: a comprehensive review. Crit. Rev. Clin. Lab. Sci. 45: 263290. http://dx.doi.org/10.1080/10408360801991055

Mohamadnejad M, Alimoghaddam K, Mohyeddin-Bonab M, Bagheri M, et al. (2007). Phase 1 trial of autologous bone

Genetics and Molecular Research 16 (1): gmr16019352 
marrow mesenchymal stem cell transplantation in patients with decompensated liver cirrhosis. Arch. Iran Med. 10: 459-466.

Oe H, Kaido T, Mori A, Onodera H, et al. (2005). Hepatocyte growth factor as well as vascular endothelial growth factor gene induction effectively promotes liver regeneration after hepatectomy in Solt-Farber rats. Hepatogastroenterology 52: 1393-1397.

Parekkadan B, van Poll D, Megeed Z, Kobayashi N, et al. (2007). Immunomodulation of activated hepatic stellate cells by mesenchymal stem cells. Biochem. Biophys. Res. Commun. 363: 247-252. http://dx.doi.org/10.1016/j. bbrc.2007.05.150

Petersen BE, Bowen WC, Patrene KD, Mars WM, et al. (1999). Bone marrow as a potential source of hepatic oval cells. Science 284: 1168-1170. http://dx.doi.org/10.1126/science.284.5417.1168

Pol S, Carnot F, Nalpas B, Lagneau JL, et al. (2004). Reversibility of hepatitis C virus-related cirrhosis. Hum. Pathol. 35: 107-112. http://dx.doi.org/10.1016/j.humpath.2003.08.012

Qian Z, Shang MM, Ling QF, Wu XP, et al. (2014). Hepatoprotective effects of loach (Misgurnus anguillicaudatus) lyophilized powder on dimethylnitrosamine-induced liver fibrosis in rats. Arch. Pharm. Res. 2014: 1-12.

Russo FP, Alison MR, Bigger BW, Amofah E, et al. (2006). The bone marrow functionally contributes to liver fibrosis. Gastroenterology 130: 1807-1821. http://dx.doi.org/10.1053/j.gastro.2006.01.036

Saito T, Okumoto K, Haga H, Nishise Y, et al. (2011). Potential therapeutic application of intravenous autologous bone marrow infusion in patients with alcoholic liver cirrhosis. Stem Cells Dev. 20: 1503-1510. http://dx.doi.org/10.1089/ scd.2011.0074

Sakaida I, Terai S, Nishina H and Okita K (2005). Development of cell therapy using autologous bone marrow cells for liver cirrhosis. Med. Mol. Morphol. 38: 197-202. http://dx.doi.org/10.1007/s00795-005-0298-Z

Schilsky ML (2009). Wilson disease: current status and the future. Biochimie 91: 1278-1281. http://dx.doi.org/10.1016/j. biochi.2009.07.012

Schwartz RE, Reyes M, Koodie L, Jiang Y, et al. (2002). Multipotent adult progenitor cells from bone marrow differentiate into functional hepatocyte-like cells. J. Clin. Invest. 109: 1291-1302. http://dx.doi.org/10.1172/JCI0215182

Terai S, Ishikawa T, Omori K, Aoyama K, et al. (2006). Improved liver function in patients with liver cirrhosis after autologous bone marrow cell infusion therapy. Stem Cells 24: 2292-2298. http://dx.doi.org/10.1634/ stemcells.2005-0542

Usunier B, Benderitter M, Tamarat R and Chapel A (2014). Management of fibrosis: the mesenchymal stromal cells breakthrough. Stem Cells Int. 2014: 340257. http://dx.doi.org/10.1155/2014/340257

Wallace K, Burt AD and Wright MC (2008). Liver fibrosis. Biochem. J. 411: 1-18. http://dx.doi.org/10.1042/BJ20071570

Yang LM (2009). Research on mensenchymal stem cells transplantation for the treatment of acute and chronic liver injury. Doctoral thesis, Jilin University. 